\title{
Estomas intestinais (ileostomias e colostomias) e anastomoses intestinais
}

\section{Intestinal stomas (Ileostomy and Colostomy) and intestinal anastomosis}

José J. Ribeiro da Rocha

\begin{abstract}
RESUMO
Estomas intestinais consistem na exteriorização do íleo ou cólon para o meio externo através da parede abdominal. Anastomoses intestinais são suturas entre dois segmentos do tubo digestivo para a reconstituição do trânsito intestinal. Tipos, classificação, indicações, complicações e a técnica são discutidos.

Palavras-chave: Estomas Cirúrgicos. Ileostomia. Colostomia. Anastomoses intestinais.
\end{abstract}

\section{Definição}

Exteriorização do íleo ou do cólon para o meio externo através da parede abdominal por tempo indeterminado

\section{Introdução}

A confecção de um estoma intestinal é um procedimento comum nas cirurgias do trato digestivo. Os estomas do segmento distal do intestino delgado (íleo) são denominados ileostomias e os do intestino grosso são as colostomias.

Os estomas intestinais são feitos em alças com mobilidade e comprimento adequados, que facilitem sua exteriorização através da parede abdominal. Dessa maneira os segmentos mais apropriados para a confecção de um estoma intestinal são o íleo, o cólon transverso e o sigmóide.

\section{Tipos e classificação dos estomas intestinais}

Os estomas intestinais podem ser temporários (transitórios) ou definitivos (permanentes).

Quanto ao modo de exteriorização na parede abdominal, pode-se fazê-los de duas maneiras: 1 - em alça (duas bocas), há exteriorização de toda a alça e abertura apenas de sua parede anterior, ficando duas bocas unidas pela parede posterior; 2- terminal (uma boca), nessa situação exterioriza-se a alça já seccionada com apenas uma boca.

\section{Indicações}

Obstruções intestinais: agenesias e atresias anorretais, megacólon congênito (doença de Hirschsprung), neoplasias, volvo, doença diverticular, colite isquêmica.
Docente. Disciplina de Coloproctologia. Departamento de Cirurgia e Anatomia da Faculdade de Medicina de Ribeirão Preto da USP.
Correspondência: Departamento de Cirurgia e Anatomia da FMRP-USP. Hospital das Clínicas da FMRP-USP - 9aa andar Avenida Bandeirantes, 3900 / 14048-900 - Ribeirão Preto/SP

Artigo recebido em 20/07/2010 Aprovado para publicação em 24/02/2011 
Perfurações do cólon: neoplasias, doença inflamatória intestinal (doença de Cröhn, retocolite ulcerativa), doença diverticular, colite isquêmica.

Traumas: penetrante (arma branca ou de fogo), fechado e empalação.

Fístulas: anorretais, reto-vaginais, reto-vesicais.

Proteção de anastomoses de alto risco: colorretais, colo-anais e ileo-anais.

\section{Complicações}

Precoces: isquemia ou necrose da alça exteriorizada, sangramento, retração, infecção, edema, dermatite peri-estomal.

Tardias: estenose e obstrução, prolapso, hérnia para-estomal, fístulas.

\section{Considerações}

A confecção adequada de um estoma é vital na qualidade de vida do paciente, ao qual deve ser esclarecido com detalhes, as razões de sua necessidade, se será um estoma temporário ou permanente, as possíveis complicações e os cuidados no manuseio e manutenção do estoma.

Os aspectos psicossociais e sexuais do paciente estomizado são relevantes na rotina de sua vida. Para que haja uma adaptação do paciente frente a esse novo contexto, é necessário uma atividade multidisciplinar composta por médicos, enfermeiros, psicólogos e estomaterapêutas, sendo estes, profissionais especializados em estomas, que orientam medidas e cuidados com o estoma desde o período pré-operatório.

A colostomia perineal continente é uma opção tática nas ressecções do reto e do ânus que evita a colostomia abdominal, posicionando-se a boca do cólon remanescente no períneo, à semelhança de um neo-ânus, permite que sejam feitas lavagens periódicas para limpeza do cólon e evitar incontinência do estoma. Nesse procedimento não há necessidade de dispositivos coletores.

\section{Técnica}

1. O local mais adequado para se exteriorizar o intestino está localizado lateralmente à linha média da parede abdominal, através do músculo reto- abdominal. Em todas as operações abdominais, quando há previsão de se fazer um estoma, a incisão deve ser na linha mediana, preservando as laterais do abdômen para possíveis estomas.
2. A incisão na pele, tecido subcutâneo e aponeurose é transversa, de 4 a $5 \mathrm{~cm}$, localizada $4 \mathrm{~cm}$ acima e lateralmente à cicatriz umbilical se a colostomia for no cólon transverso e $4 \mathrm{~cm}$ abaixo e lateralmente se for ileostomia (à direita) ou se for sigmoidostomia (à esquerda).

3. Na ileostomia ou colostomia em alça, ao se exteriorizar a alça ileal ou colônica, faz-se a abertura na face antimesentérica e sutura-se as bordas das duas bocas na pele (Figuras 1,2). Na colostomia ou ileostomia terminal, o íleo ou cólon é exteriorizado com uma única boca que é suturada à pele (Figu$\operatorname{ras} 3,4)$.

4. Um dos fatores importantes na técnica das ileostomias é a eversão da mucosa e protrusão da alça, o que a torna saliente, de aspecto mamilar, com 3 a 6 $\mathrm{cm}$ da borda cutânea. Dessa maneira, o líquido entérico cai diretamente na bolsa coletora, não provocando dermatite de contato pela secreção alcalina ileal. As colostomias, por sua vez, podem ficar ao nível da superfície cutânea, pois as fezes que saem do cólon, além de mais consistentes, não são irritantes devido ao pH neutro (Figuras 5, 6).

5. Para coletar os resíduos entéricos e fecais das ileostomias e colostomias são utilizados dispositivos chamados bolsas de colostomias, compostas por uma placa adesiva que adere à pele em volta do estoma e sobre ela uma bolsa coletora (Figura 7).

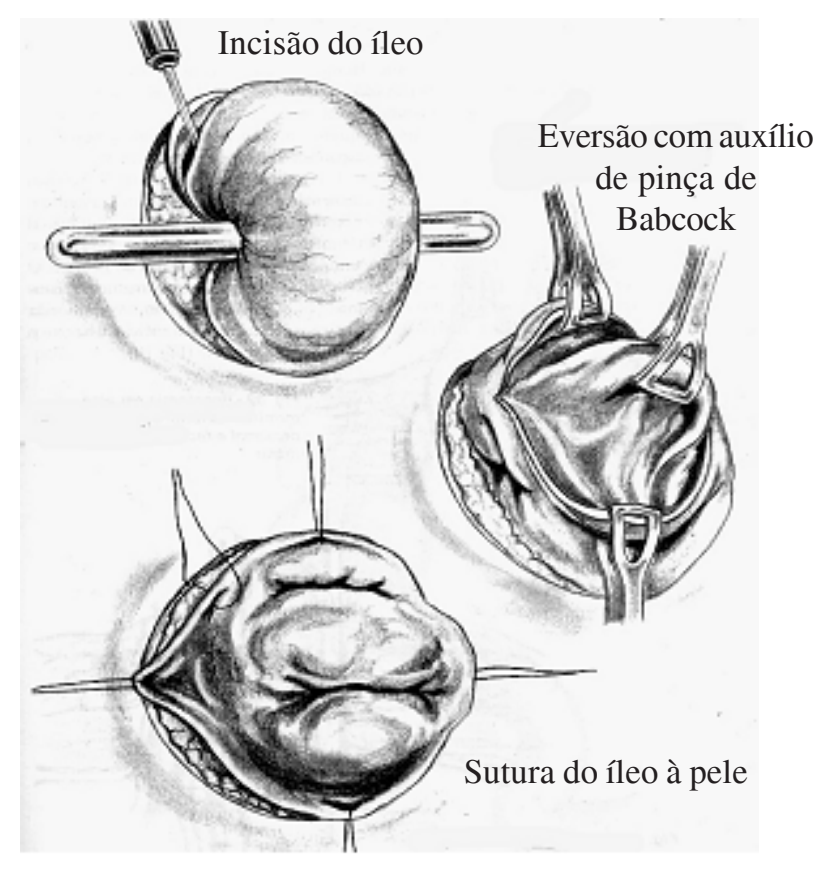

Figura 1. Esquema da confecção da ileostomia em alça. 


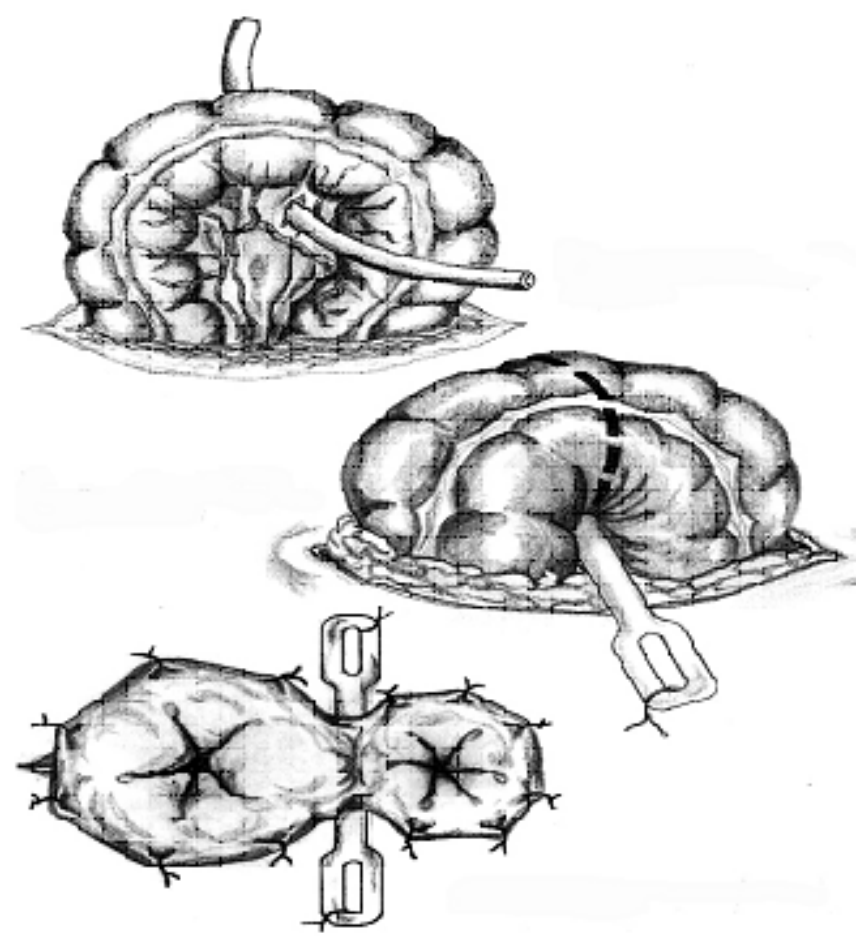

Figura 2. Esquema da confecção da colostomia em alça.

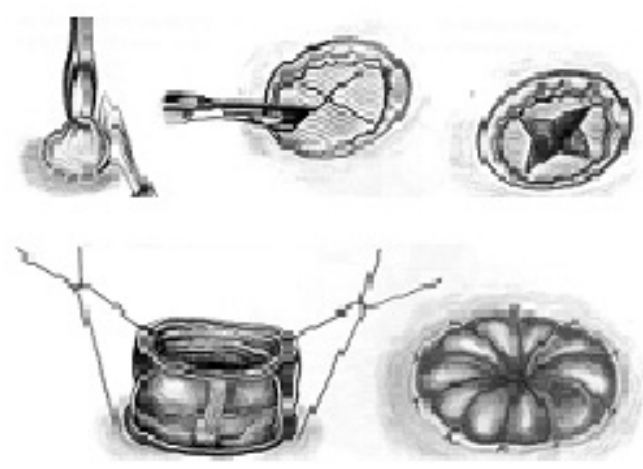

Figura 3. Esquema da confecção da colostomia terminal.

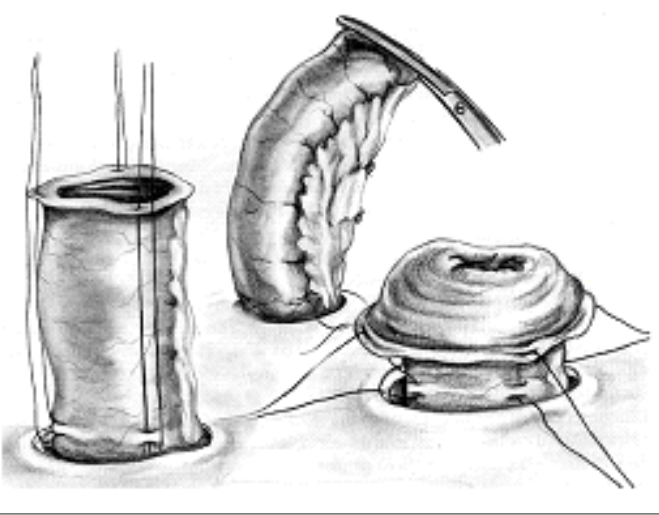

Figura 4. Esquema da confecção da ileostomia terminal.

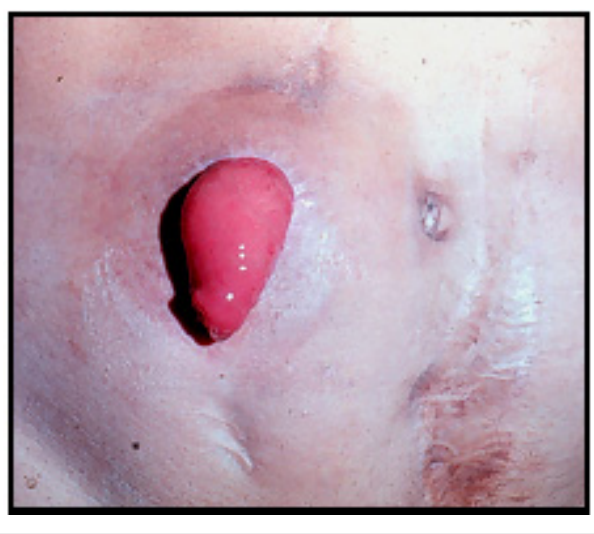

Figura 5. lleostomia terminal.

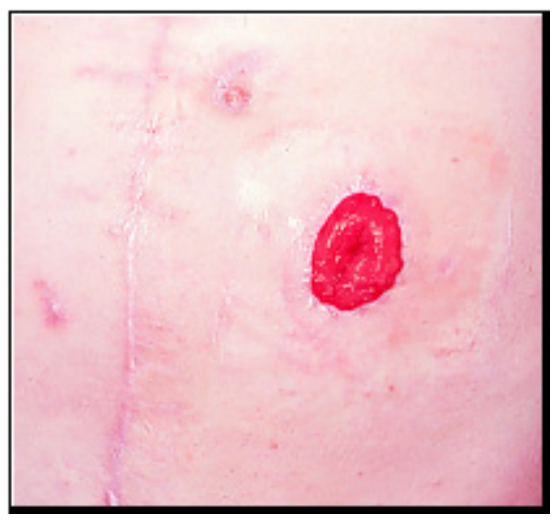

Figura 6. Colostomia terminal.
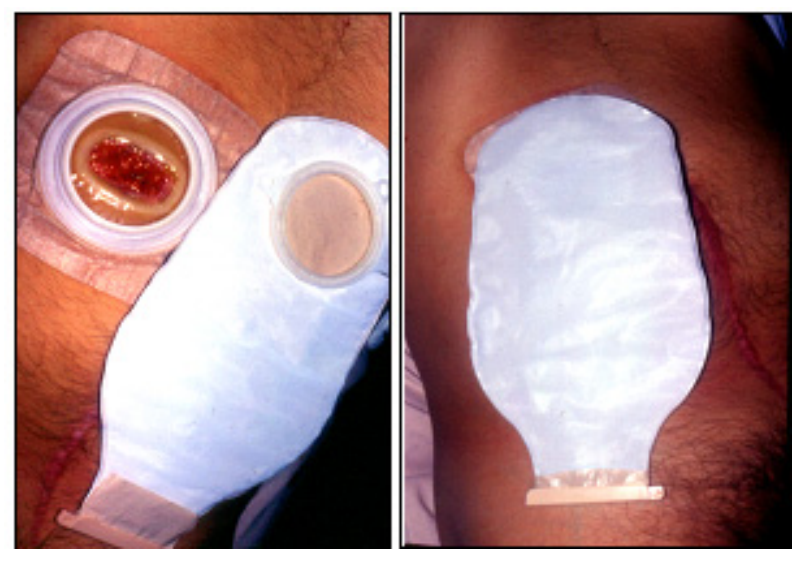

Figura 7. Bolsa de colostomia (placa e coletor). 


\section{Anastomoses intestinais}

\section{Introdução}

As anastomoses intestinais são suturas realizadas entre dois segmentos intestinais com o fim de reconstituir o trânsito intestinal regular.

Habitualmente estão indicadas e são confeccionadas após ressecção de algum segmento do tubo digestivo. Essas ressecções, como por exemplo, enterectomias, colectomias, gastrectomias, ocorrem em razão de neoplasias, isquemia intestinal por torção de alça, embolia, trombose ou hérnias estranguladas, nos traumas, nas doenças inflamatórias intestinais e na doença diverticular.

Como uma anastomose intestinal é uma emenda entre dois segmentos do tubo digestivo, ao descrevêla citamos primeiramente o segmento proximal e depois o distal, por exemplo: gastro-êntero anastomose, anastomose íleo-cólica ou colorretal.

\section{Fundamentos}

Ao se realizar uma anastomose intestinal, são pré-requisitos essenciais:

- Vascularização (irrigação sangüínea) em boas condições na linha de sutura, não pode estar isquêmica.

- Não haja tensão na linha de sutura

- Boas condições sistêmicas do paciente (não estar em choque hipovolêmico, anêmico ou desnutrido).

\section{Outros requisitos importantes:}

- Hemostasia no local da sutura.

- Remover tecidos desvitalizados.

- Coagulação adequada de todas as camadas da parede intestinal

- Não haja nenhuma compressão ou obstrução a montante da anastomose

- Boas condições loco-regional da cavidade peritoneal
- Manuseio delicado da alça com as pinças de sutura

- Uso de material adequado (porta agulhas, agulhas finas e não traumáticas e fios com calibre e material corretos).

\section{Técnica}

São muitas as técnicas utilizadas, assim como os materiais empregados. As suturas podem ser feitas em um ou dois planos. Os pontos que são passados de 3 a 4 mm de distância um do outro podem ser separados ou em uma sutura contínua.

A sutura pode envolver todas as camadas (pontos totais) ou evitar a mucosa (ponto subtotal extramucoso) ou ser apenas na seromuscular (Figu$\operatorname{ras} 8,9,10,11,12$ ).

O material (agulhas e fios) é variável, sendo utilizados fios absorvíveis ou inabsorvíveis, com agulhas não traumáticas, 3-0 ou 4.0 de calibre, se possível, monofilamentares.

Outro material utilizado para as anastomoses intestinais são os grampos metálicos, através dos grampeadores circulares ou retos, indicados em anastomoses especiais como as colorretais baixas na pelve, as esôfago-gástricas e as entero-anastomoses de maior risco de deiscência e estenose ou em que haja dificuldade técnica na sutura manual (Figuras 13,14).

Para se descrever as anastomoses intestinais quanto à emenda dos dois segmentos, cita-se inicialmente o segmento proximal e depois o distal. A sutura pode ser feita entre as duas bocas terminais do segmento ressecado, chamada de anastomose términoterminal, ou entre as bordas laterais dessas extremidades, conhecida como anastomose látero-lateral. Quando a boca terminal é do lado proximal e de outro lado é a borda lateral, é denominada anastomose término-lateral, se oposto, será anastomose látero-terminal (Figura 15).

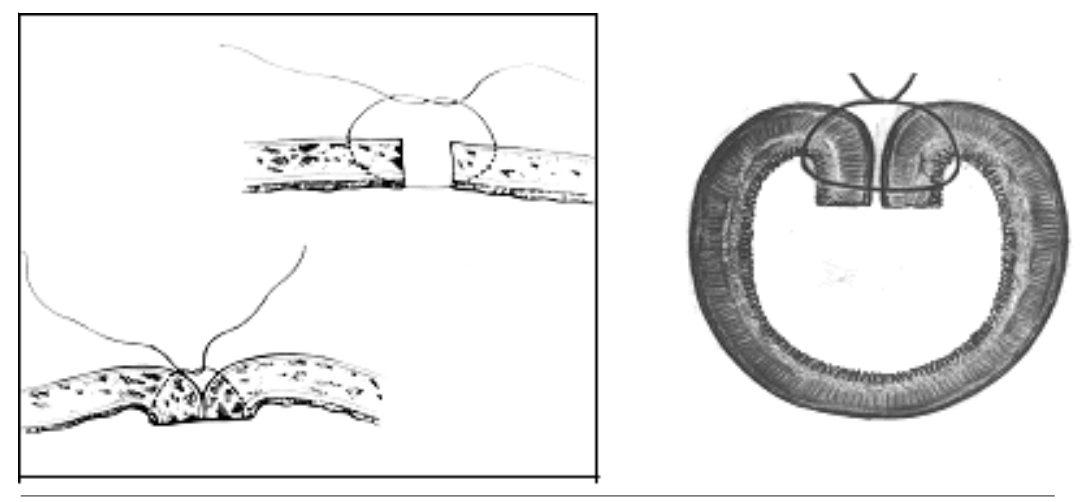

Figura 8. Ponto separado total - plano único (nó externo) 


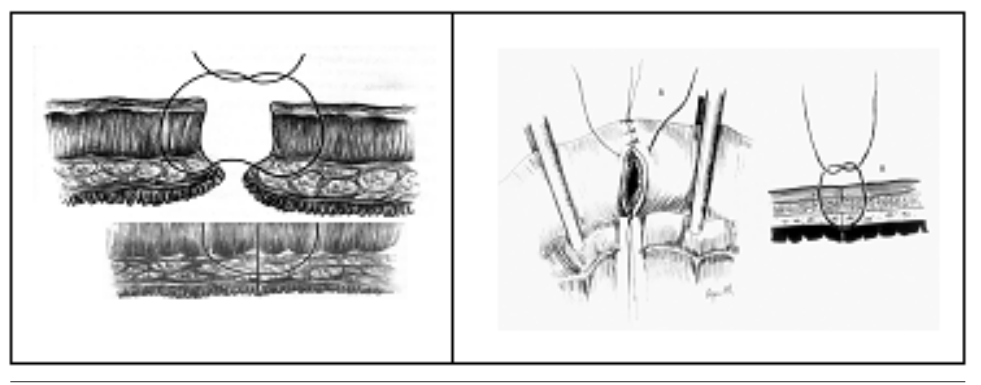

Figuras 9 e 10 . Ponto separado extramucoso plano único (nó externo)
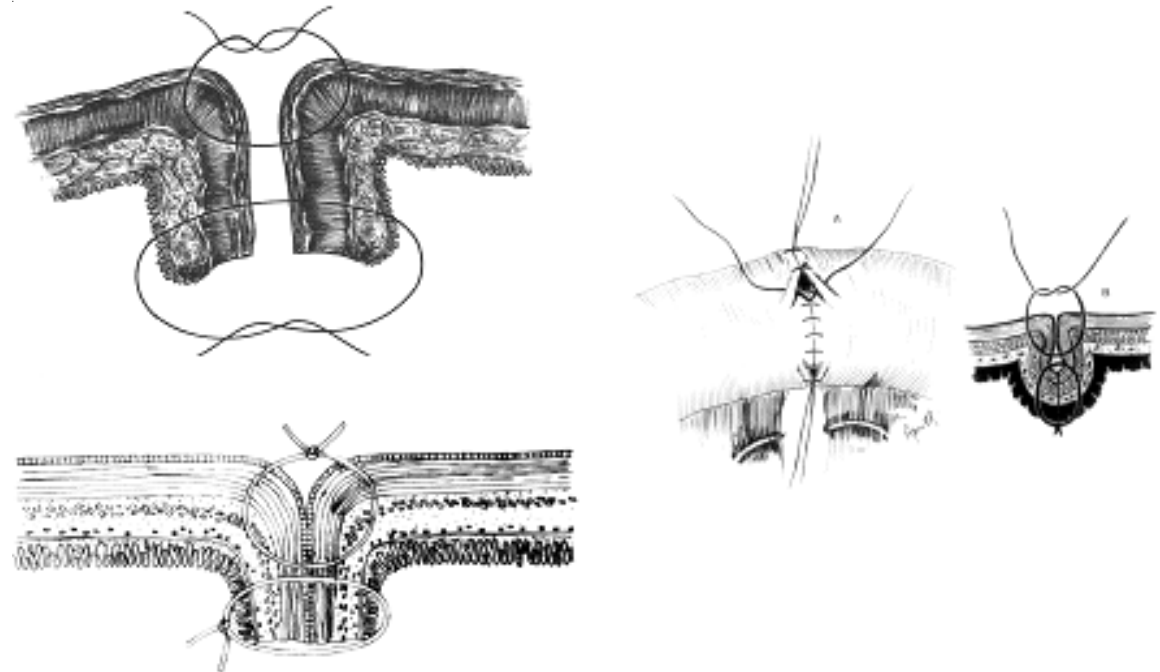

Figura 11. Ponto separado - dois planos de sutura (total e seromuscular).

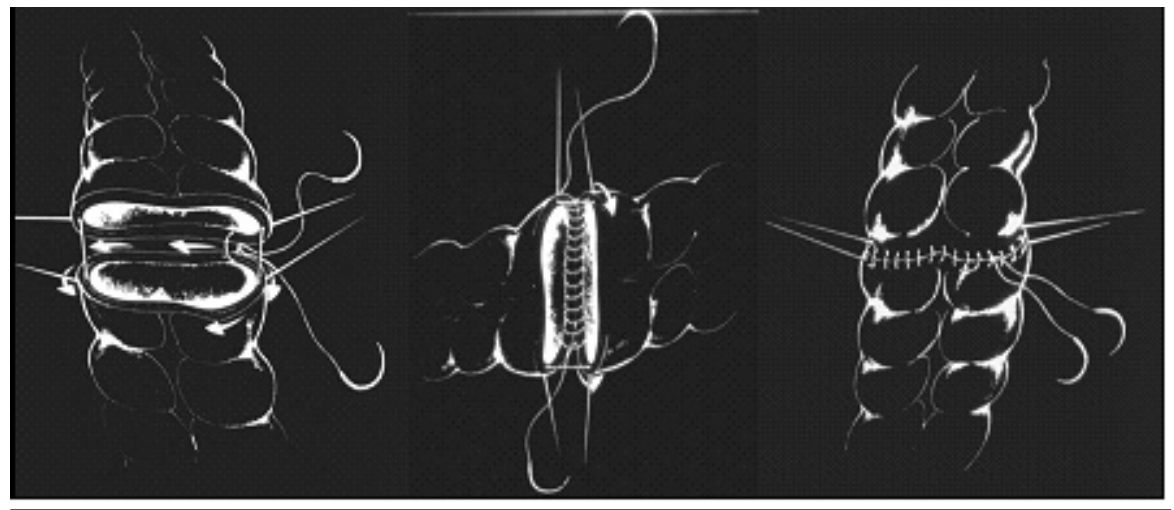

Figura 12. Sutura contínua em plano único.

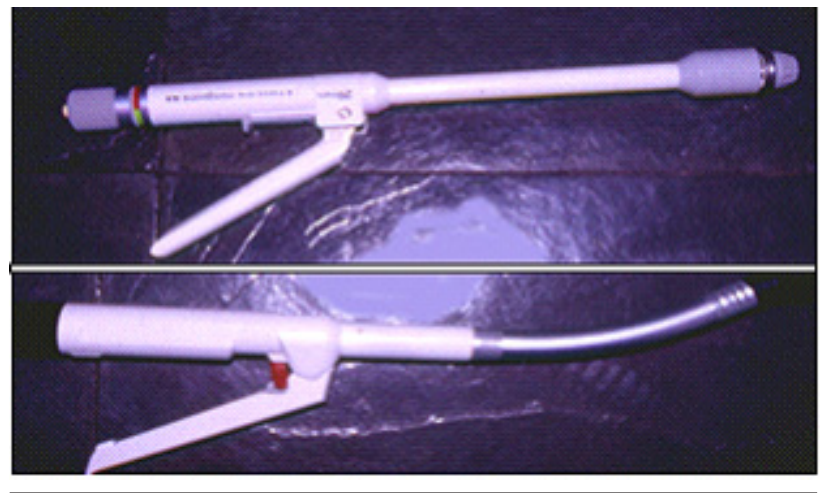

Figura 13. Grampeadores circulares. 


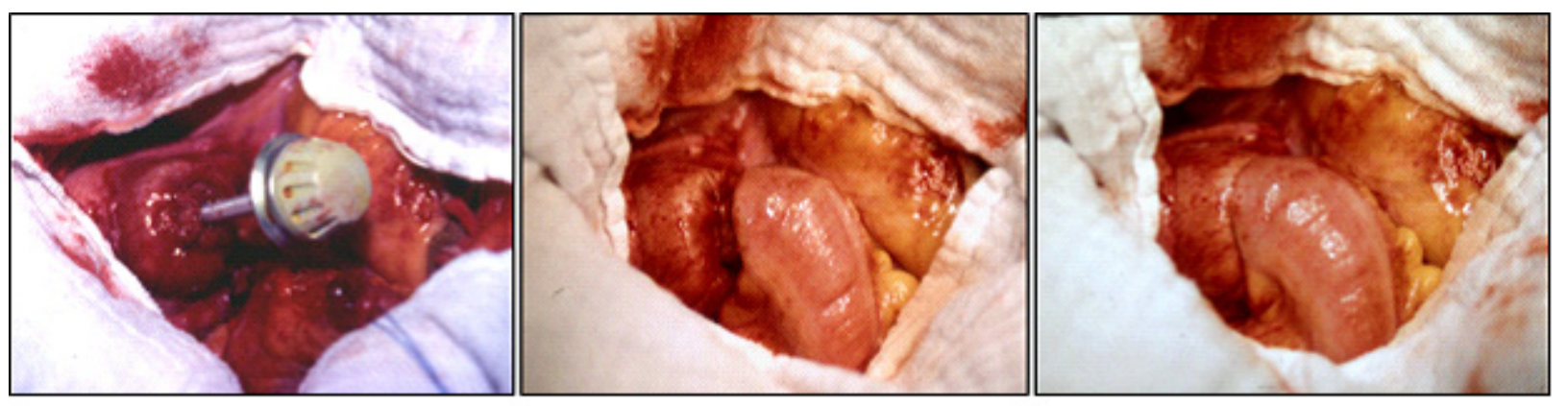

Figura 14. Anastomose colorretal com grampeador circular.

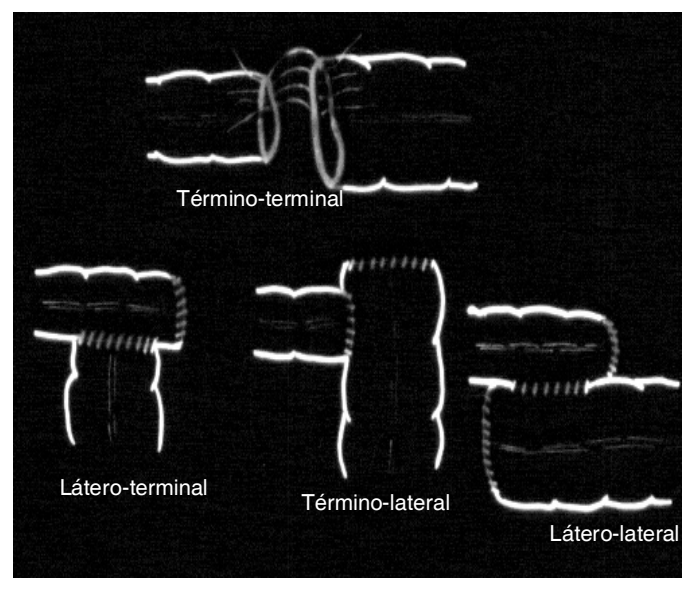

Figura 15. Tipos de anastomoses quanto à emenda dos segmentos.

\section{ABSTRACT}

Intestinal stomas consist of ileum or colon exteriorization through the abdominal wall. Intestinal anastomosis are sutures between two segments of the digestive tract to replenish the intestinal tract. Types, classification, indications, complications, and techniques will be discussed.

Keywords: Surgical Stomas. Ileostomy. Colostomy. Intestinal anastomosis.

\section{Referência Bibliográfica}

1. Rocha JJR. Coloproctologia - princípios e práticas. Editora Atheneu; 2a ed. 2011.

2. Virgínio C Tosta de Souza. Colo-proctologia. Editora MEDSI; $4^{a}$ ed. 1999. 